\title{
THE ROLE OF NEEDLE IN FORMULATION OF pH SENSITIVE SWELLABLE MICROBEADS PREPARED WITH HYDROPHILIC POLYMERS FOR ATORVASTATIN AND THEIR CHARACTERIZATION STUDIES
}

\author{
K.V. RAMANA REDDY ${ }^{*}$, M.V.NAGABHUSHANAM ${ }^{2}$
}

${ }^{1}$ Department of Pharmaceutics, Research Scholar, Acharya Nagarjuna University, Guntur, Andhra Pradesh. India - 522002, ${ }^{2}$ Department of Pharmaceutics, Hindu College of Pharmacy, Guntur, Andhra Pradesh. India-522002.

Email: ramanapharm1979@gmail.com

Received: 06 Jan 2017, Revised and Accepted: 17 Apr 2017

\section{ABSTRACT}

Objective: The aim of the study was to develop and characterize mucoadhesive microbeads for oral sustained release of atorvastatin by using hydrophilic polymers and application of different process variables in designing of $\mathrm{pH}$ sensitive swellable microbeads.

Methods: Microbeads were prepared by ionic gelation method. The compatibility studies of atorvastatin with polymers were investigated by differential scanning calorimeter and fourier transform infrared spectroscopy studies. In this work process variable like optimization of curing agents and their quantity, effect of rpm, and their influence in drug entrapment were studied. Prepared beads were characterized for particle size, swelling index, erosion studies and drug release studies.

Results: Mixture of alginate and carbopol $934 \mathrm{P}$ at $3.3 \% \mathrm{w} / \mathrm{v}$ shows sustained release and good mucoadhesive capacity. Furthermore, drug loading and swelling increased with the use of a combination of polymers. On basis of in vitro release studies and swelling studies, it was observed that sodium alginate coated with carbopol $934 \mathrm{P}$ showed sustained release of $84.5 \%$ at end of $10 \mathrm{~h}$ in 6.8 phosphate buffer. The optimised batch followed peppas and higuchi release mechanism and releasing the drug by non-fickian transport.

Conclusion: The alginate beads with a combination of carbopol 934P showed a sustain release pattern. The release rate and swelling of atorvastatin beads could be adjusted by adding other hydrophilic polymers or by optimising curing agents, curing time and their volume. The zero order of drug release was confirmed for all the batches. The in vitro data was better fit to Higuchi's diffusion model and diffusion rate limited.

Keywords: Atorvastatin, Mucoadhesive microbeads, Needle effect and Sustained release

(C) 2017 The Authors. Published by Innovare Academic Sciences Pvt Ltd. This is an open access article under the CC BY license (http://creativecommons.org/licenses/by/4.0/) DOI: http://dx.doi.org/10.22159/ijap.2017v9i3.16952

\section{INTRODUCTION}

Among the multiple routes of drug delivery [1], oral route is the most suitable, used and most accepted one by the patients for the delivery of the therapeutically active drugs over the past few years, many controlled releases, Controlled release drug delivery systems have been developed using a variety of innovative techniques with wide variety of polymeric matrices.

By adopting controlled drug delivery many of the obstacles, for example, they maximize drug absorption, reduce peak plasma fluctuations and minimize potential side effects etc [2, 3] will be overcome and getting much patient compliance [4] and improve the rate of bioavailability. Ionic gelation technique involves ionic crosslinking between polyelectrolyte biopolymers such as alginates, chitosan, etc. and counterions to produce a cross-linked matrix which would provide the desired controlled release rate of the drug molecule. From a polymer chemistry viewpoint, the development of interpenetrating network polymers (IPNs) of sod. Alginate is attractive because, by definition, the IPNs contain two polymers, each in a network form, which can be cross-linked in the presence of each other to give a three-dimensional network structure producing free volume for the easy encapsulation of drugs easily. Bio/ mucoadhesive [5] microspheres have few advantages such as marked efficient absorption and improved the rate of bioavailability of drugs owing to high surface to volume ratio, a much more close contact with the mucus layer following oral consumption and specific targeting of drugs to the desired absorption site.

Atorvastatin is a new class of lipid-lowering compound that selectively inhibit the intestinal absorption of cholesterol and decrease cholesterol absorption. After oral administration alone, atorvastatin is rapidly absorbed, reach maximum plasma concentrations within 1-2 $\mathrm{h}$. Atorvastatin belongs to biopharmaceutics classification system class II category, showing low oral bioavailability $(12 \%)$ [6], due to low aqueous solubility $(0.15 \mathrm{mg} / \mathrm{ml})$, high presystemic clearance in the gastrointestinal mucosa (80\%), and extensive hepatic first-pass effect, thus their bioavailability depends on dissolution features. Its having half-life is 11-19 h in humans [7-9]. It is insoluble in aqueous solutions at $\mathrm{pH} 4$ and below. It is insoluble in an aqueous solution of $\mathrm{pH} 4$ and below, it is very slightly soluble in water and $7.4 \mathrm{pH}$ phosphate buffer. The intestinal permeability of atorvastatin is high at the physiologically relevant intestinal $\mathrm{pH}[10]$. However, it is reported that the absolute bioavailability of atorvastatin is $12 \%$ after a $40 \mathrm{mg}$ oral dose [11]. In view of its long biological half-life and less bioavailability of atorvastatin and the associated side effects, we have chosen atorvastatin for developing the controlled release beads with sodium alginate as a coating polymer.

Polymers belong to the class of polysaccharides are widely used in oral drug delivery systems because of their simplicity to obtain the desired drug delivery system and drug release profile. In our recent paper, we have shown the ability of hydroxypropyl methyl cellulose $\mathrm{K} 15 \mathrm{M}$, carbopol 934P and polyvinyl pyrrolidine (PVP) polymers to form a high-viscosity hydrogels using a very small amount of hydrophilic materials. In our present study, we extend the investigation by using polymers in combination with $\mathrm{Na}$. alginate to form hydrogel complex beads and to check the sustainability of the therapeutic effect of drug obtained from the matrix. Among existence of various natural polymers, alginates have been used as matrices to achieve controlled release drug delivery due to their hydrogel-forming properties. The sodium alginate [12] has been used as a controlled release matrix material in medicine and it can absorb water 200-300 times to their own weight. It consists of linear polymer of $ß-(1-4)$ mannuronic acid (M) and (1-4) guluronic acid (G) residues in varying proportions and arrangements. It has been shown that the $G$ and $M$ units are joined together anonymous. These residues are arranged in homopolymeric and heteropolymeric blocks.

Accordingly, the objective of the current study was to optimise the composition of alginate beads with hydrophilic polymers to produce 
stable beads with optimum specifications. The major objective of the current experiment is made with different objectives i.e. the effect of conc. of sodium alginate, the effect of tri and divalent curing agents, the effect of rpm, effect of curing volume and effect of curing time.

In the present study, we have aimed to formulate the stable alginate beads by ionic gelation technique with hydrophilic polymers naming carbopol 934P, polyvinyl pyrrolidone (PVP) and hydroxypropyl methyl cellulose K15 (HPMC K15). These polymers undergoes ionic interactions with di and trivalent compounds, for this reason, we have used both metal ions as $\mathrm{cacl}_{+2}$ and $\mathrm{alcl}_{+3}$ as curing agents for the cross linking of alginate material and formed beads were evaluated the characterization of beads.

\section{MATERIALS AND METHODS}

Atorvastatin pure drug sample obtained from Aizant, Hyderabad, India, sodium alginate $45 \mathrm{cps}\left(1 \% \mathrm{w} / \mathrm{v}\right.$ solution in water at $\left.25^{\circ} \mathrm{C}\right)$, carbopol 934P (SD fine chemicals. Mumbai), hydroxypropyl methyl cellulose K15 M, polyvinyl pyrrolidone, aluminium chloride dihydrate, calcium chloride, potassium dihydrogen phosphate, potassium hydroxide pellets (E. Merck, India), ethanol and sodium lauryl sulphate (SLS) were used. All other used reagents were of analytical grade.

\section{Equipment}

Weighing balance, sonicator (Remi model, Mumbai), homogenizer, (Remi, India),USP tablet disintegrating test apparatus,dissolution test apparatus USP, model TDT-08L,electro lab, uv-visible spectrophotometer, scanning electron microscope (SEM; S-4100,
Hitachi, Japan), X-Ray diffractometer, Bruker spectrophotometer (Model-220, Germany) and syringe needles 22 G, 24 G etc.

\section{Preparation of cross-linked swellable alginate hydrogel beads}

Cross-linked alginate beads were prepared by adopting orifice gelation technique which is simple, easiest and simple method of entire microencapsulation techniques. For micro beads formation, $100 \mathrm{ml}$ of $3 \% \mathrm{w} / \mathrm{v}$ aqueous solution of sodium alginate which contains atorvastatin $100 \mathrm{mg}$ and $0.30 \% \mathrm{w} / \mathrm{v}$ of different mucoadhesive hydrophilic polymers (which already dispersed in water and kept aside one night to develop interpenetrated network) naming carbopol 934P, polyvinyl pyrrolidine and hydroxypropyl methyl cellulose K15M. After uniform dispersion of above mucilage, it was discharged dropwise from syringe needle size-22 needle into $100 \mathrm{ml}$ of an aqueous $5 \% \mathrm{w} / \mathrm{v}$ aluminium chloride/calcium chloride solution being stirred at different rpm. Keep distance between needle to curing medium at least $15 \mathrm{cms}$. gap to get stable spherical beads. Since sodium alginate gel can easily be formed by this ionic interaction in an aqueous medium, gel beads are commonly obtained by dropping solutions of sod. alginate into a solution which contains different divalent and trivalent electrolytes. Formed soft beads cured for a period of 30 to $60 \mathrm{~min}$. into curing solution to harden the surface of soft beads. The concentration of Alcl $_{+3}$ in the solution ranged from $5 \% \mathrm{w} / \mathrm{v}$. The stirring was continued for one hour and make sure that free air bubble should be made throughout polymer solution by subjecting to sonicator for more than $1 \mathrm{~h}$ and formed the aluminium alginate beads were separated by filtration and decantation, obtained beads washed with distilled water three times continuously to remove traces of curing medium, and make air dried overnight.

Table 1: Formulation of atorvastatin microbeads

\begin{tabular}{|c|c|c|c|c|c|c|}
\hline Batch code & Sodium alginate $(\% \mathrm{w} / \mathrm{v})$ & Atorvastatin (mg) & Curing agent & Curing agent $(\%)$ & Curing time (h) & RPM \\
\hline $\mathrm{A}$ & 2 & 100 & Cacl2 & 2.5 & 0.25 & 100 \\
\hline B & 3 & 100 & Cacl2 & 2.5 & 0.25 & 100 \\
\hline C & 4 & 100 & Cacl2 & 2.5 & 0.25 & 100 \\
\hline D & 2 & 100 & Alcl3 & 5 & 0.5 & 200 \\
\hline E & 3 & 100 & Alcl3 & 5 & 0.5 & 200 \\
\hline $\mathrm{F}$ & 4 & 100 & Alcl3 & 5 & 0.5 & 200 \\
\hline G & 3 & 100 & Alcl3 & 5 & 1 & 200 \\
\hline $\mathrm{H}$ & 3 & 100 & Alcl3 & 5 & 1 & 300 \\
\hline
\end{tabular}

Table 2: Formulation of optimised alginate beads with different hydrophilic polymers

\begin{tabular}{|c|c|c|c|c|c|c|c|}
\hline Code & Polymers $(3 \%+0.3 \% \mathrm{w} / \mathrm{v})$ & Drug (mg) & Curing agent & $\begin{array}{l}\text { Curing agent } \\
(\%)\end{array}$ & RPM & Curing time (h) & $\begin{array}{l}\text { Curing volume } \\
(\mathrm{ml})\end{array}$ \\
\hline A1 & Sod. Alginate+carbopol 934P & 100 & $\mathrm{Alcl}_{+3}$ & 5 & 200 & 1 & 100 \\
\hline B1 & Sod. Alginate+carbopol 934P & 100 & $\mathrm{Alcl}_{+3}$ & 5 & 200 & 1 & 150 \\
\hline $\mathrm{C} 1$ & Sod. Alginate+carbopol 934P & 100 & $\mathrm{Alcl}_{+3}$ & 5 & 200 & 1 & 200 \\
\hline D1 & Sod. Alginate+HPMC K15 & 100 & $\mathrm{Alcl}_{+3}$ & 5 & 200 & 1 & 100 \\
\hline E1 & Sod. Alginate+poly vinyl pyrrolidine & 100 & $\mathrm{Alcl}_{+3}$ & 5 & 200 & 1 & 100 \\
\hline
\end{tabular}

Table 3: List of various optimised parameters

\begin{tabular}{llllllll}
\hline S. No. & $\begin{array}{l}\text { Conc. of sodium alginate } \\
\text { (\%) }\end{array}$ & rpm & $\begin{array}{l}\text { Curing medium } \\
(\mathbf{m l})\end{array}$ & $\begin{array}{l}\text { Curing time } \\
\text { (min.) }\end{array}$ & Curing agent & $\begin{array}{l}\text { Curing agent } \\
\text { (\%) }\end{array}$ & $\begin{array}{l}\text { Syring needle } \\
\text { grade }\end{array}$ \\
\hline 1 & 3 & 200 & 100 & 60 & $\begin{array}{l}\text { Aluminium } \\
\text { chloride }\end{array}$ & 5 & $22 \mathrm{G}$ \\
\hline
\end{tabular}

\section{Experimental design}

\section{Determination of absorption maxima}

$10 \mu \mathrm{g} / \mathrm{ml}$ solutions were taken to determine absorption maxima. Initially blank buffer solution was kept and scanned in the region of 200-400 nm by using UV-visible spectrophotometer. Then drug sample was kept for analysis and scanned in the above region.

\section{Drug entrapment efficiency}

The prepared drugloaded microspheres were checked for their drug content. Accurately weighed $100 \mathrm{mg}$ of the dried microspheres were powdered and dissolved in $100 \mathrm{ml}$ phosphate buffer ( $\mathrm{pH}$ 6.8). The solution was kept overnight and then filtered using $0.45 \mu \mathrm{m}$ cellulose acetate syringe filter, after series of suitable dilutions with phosphate buffer were done, solutions were filtered and analyzed spectrophotometrically at $243 \mathrm{~nm}$ by using uv-visible spectrophotometer (UV-800 Shimadzu, Japan). The entrapment efficiency was determined using the following equation:

$$
\text { Drug entrapment }(\%)=\frac{\text { Actual drug concentration }}{\text { Theoretical drug concentration }} \times 100
$$




\section{Determination of swelling properties}

The dynamic swelling property of microbeads was determined by placing beads in the both i.e. acidic and $6.8 \mathrm{pH}$ phosphate buffer medium under standard conditions. Prepared microbeads of known weight were placed in dissolution solution for specified time and were maintained $37+0.5^{\circ} \mathrm{c}$ temperature with $70 \mathrm{rpm}$. The swollen microcapsules were collected by decantation at different intervals of time. The wet weight of the swollen alginate cross-linked microcapsules was determined by first blotting the particles with filter paper to remove absorbed water on the surface and then weighing immediately again on an electronic balance. The difference in given values give the percentage of swelling of microcapsules in the dissolution media and it was calculated by using equation.

$$
\mathrm{S}_{\mathrm{w}}=\left(\mathrm{W}_{\mathrm{t}}-\mathrm{W}_{\mathrm{o})} / \mathrm{W}_{\mathrm{o}} \times 100\right.
$$

Where Sw = percentage of swelling of microcapsules/beads, $\mathrm{Wt}=$ weight of the microcapsules at time $\mathrm{t}$, and $\mathrm{WO}=$ initial weight of the microcapsules.

\section{Erosion studies}

The dried alginate beads were weighed and placed in a dissolution basket, which contains phosphate buffer ( $\mathrm{pH} \mathrm{6.8)} \mathrm{at} 70 \mathrm{rpm}$. After every $1 \mathrm{~h}$ intervals of time, the swelled beads were removed from the basket carefully and dried at room temperature. The beads were dried after water was been removed, and the dried beads were reweighed. The beads were then placed back in the basket. This entire process lasted $11 \mathrm{~h}$. Erosion study was performed using the following formula.

$$
\% \text { weight loss }=\left(w_{0}-w_{1}\right) \times 100 / w_{0}
$$

Where Wo = Initial beads weight and W1 = weight of beads after drying.

\section{Mucoadhesive testing by in vitro wash-off test}

The functionality mucoadhesive property of the alginate base microbeads was evaluated by in vitro wash off test. Collect freshly excised pieces of the intestinal mucosa $\left(3 \times 3 \mathrm{~cm}^{2}\right)$ from sheep were mounted onto glass slides $(3 \times 2$ inches $)$ with cyanoacrylate glue. Approximately 50 micro beads were placed and spread onto each wet rinsed tissue specimen, and immediately the slide was hung onto the arm of a USP tablet disintegrating test apparatus. The tissue specimen was given a slow, regular up-and-down movement in the disintegration fluid at $37^{\circ} \mathrm{C}$ contained in a one-liter basket vessel and maintain baskets move up and down continuously at $70 \mathrm{rpm}$. After the definite time intervals, the machine was stopped and the number of microcapsules still adhering to the tissue was counted. (Gastric $\mathrm{pH}$ ) $0.1 \mathrm{~N} \mathrm{Hcl}, \mathrm{pH} 1.2$ and (intestinal $\mathrm{pH}$ ) phosphate buffer of pH 6.8 were used as test fluids. The difference in adherence of swelled alginate beads to glass slides before and after were given knowledge of the mucoadhesive strength of microbeads.

\section{Scanning electron microscopy}

The surface morphology of microbeads was investigated by using scanning electron microscope (USA model). A known amount of sample were placed on a brass stub using double-sided adhesive tape and made electrically conductive by coating with a thin layer of gold and SEM images were observed at different accelerating voltage [14-15].

\section{Differential scanning calorimetry}

DSC studies were carried out on the thermal analyzer (TA-60WS), shimadzu. A few milligrams of the sample, were hermetically sealed into aluminium pans and heated under a nitrogen atmosphere with the heating rate of $10^{\circ} \mathrm{C} / \mathrm{min}$. [16-18]

\section{X-ray diffraction study}

Change in crystalline structure of the drug when loaded into alginate beads was measured by using X-Ray diffract meter [19].

\section{In vitro release studies}

in vitro release of prepared microbeads were assessed in triplicate by using united states pharmacopoeia (USP) dissolution type II apparatus (Basket Type) at $37 \pm 0.5^{\circ} \mathrm{C}$ under $70 \mathrm{rpm}$. A freshly prepared phosphate buffer of $\mathrm{pH} 6.8(900 \mathrm{ml})$ was used as dissolution medium throughout the process. Microbeads containing $20 \mathrm{mg}$ equivalent of the drug was placed in $900 \mathrm{ml}$ of dissolution medium (phosphate buffer $\mathrm{pH} 6.8$ with methanol in 9:1ratio). The revolution speed of the basket was maintained at $70 \mathrm{rpm}$. At different time intervals, $5 \mathrm{ml}$ of dissolution medium was collected and the dissolution media was always replenished with a fresh stock solution of 6.8 buffer solution. Suitable dilutions were done with the dissolution fluid; the samples were analyzed for the drug concentration by using UV-Visible spectrophotometer (Shimadzu, Japan) at $243 \mathrm{~nm}$. [20].

\section{Release kinetics}

To study the release kinetics, data obtained from in vitro dissolution study was fitted in various kinetic models: zero order as cumulative percent of drug released vs. time, first order as log cumulative percentage of drug remaining vs. time and Higuchi's model as cumulative percent drug released vs. square root of time, Hixon crowel describes the release from systems when there is a change in a surface area and diameter of particles. To determine the mechanism of drug release [21], the data was fitted into Korsmeyer and Peppas equation as $\log$ cumulative percentage of drug released vs. $\log$ time and the exponent $\mathrm{n}$ was calculated from the slope of the straight line. For slab matrix, if the exponent is 0.5 , then diffusion mechanism is fickian; if $0.5<\mathrm{n}<1.0$, then it an indication of anomalous transport. If $\mathrm{n}$ is 1.0 , it is case II transport and if $n>1.0$, then it is confirmed as super case II transport or non-fickian diffusion.

\section{RESULTS AND DISCUSSION}

\section{UV spectra ( $\lambda$ max) of atorvastatin calcium}

$10 \mu \mathrm{g} / \mathrm{ml}$ solutions of atorvastatin were taken to determine absorption maxima. Atorvastatin sample was observed scanned in the range of 200-400 $\mathrm{nm}$. Absorption maxima were found to be 243 $\mathrm{nm}$. Hence all further analysis was carried out at 243.

\section{Atorvastatin solubility in various buffers}

Pure drug atorvastatin undergoing solubility less than $25.04 \mu \pm 0.46$ $\mu \mathrm{gm} / \mathrm{ml}$. Atorvastatin has the highest solubility in $\mathrm{pH} 6.8$ phosphate buffer with $1.5 \%(\mathrm{w} / \mathrm{v})$ sodium lauryl sulphate $(217.1 \mu \mathrm{g} / \mathrm{ml})$. The addition of SLS increased the solubility of atorvastatin in $\mathrm{pH} 6.8$ phosphate buffer. The solubility of atorvastatin was highest in $\mathrm{pH} 6.8$ buffer compared with other buffers; hence, further dissolution testing of atorvastatin microspheres was performed by using pH 6.8 phosphate buffer with the addition of sodium lauryl sulphate in desired concentrations of $0.5 \%, 1 \%$, and $1.5 \%(\mathrm{w} / \mathrm{v})$. The solubility values of atorvastatin in different buffer medium were predicted in above table 4 .

Table 4: List of solubility values in different buffers

\begin{tabular}{lll}
\hline S. No. & Medium & Solubility $\mathbf{~ m g} / \mathbf{m l}$ \\
\hline 1 & 6.0 Phosphate buffer & $20.12 \pm 1.12$ \\
2 & 6.8 Phosphate buffer & $70.12 \pm 2.34$ \\
3 & 7.4 Phosphate buffer & $68.89 \pm 0.32$ \\
4 & 0.5 \% SLS in 6.8 Phosphate buffer & $72.5 \pm 2.64$ \\
5 & $1 \%$ SLS in in 6.8 Phosphate buffer & $115.12 \pm 7.36$ \\
6 & $1.5 \%$ SLS in in 6.8 Phosphate buffer & $217 . \pm 0.89$ \\
7 & $0.5 \%$ SLS in Phosphate buffer 7.4 & $90.34 \pm 0.56$ \\
8 & $1 \%$ SLS in Phosphate buffer 7.4 & $97.12 \pm 6.45$ \\
9 & $1.5 \%$ SLS in Phosphate buffer 7.4 & $126,23 \pm 2.24$ \\
\hline
\end{tabular}

$* n=3$ (average \pm SD) 


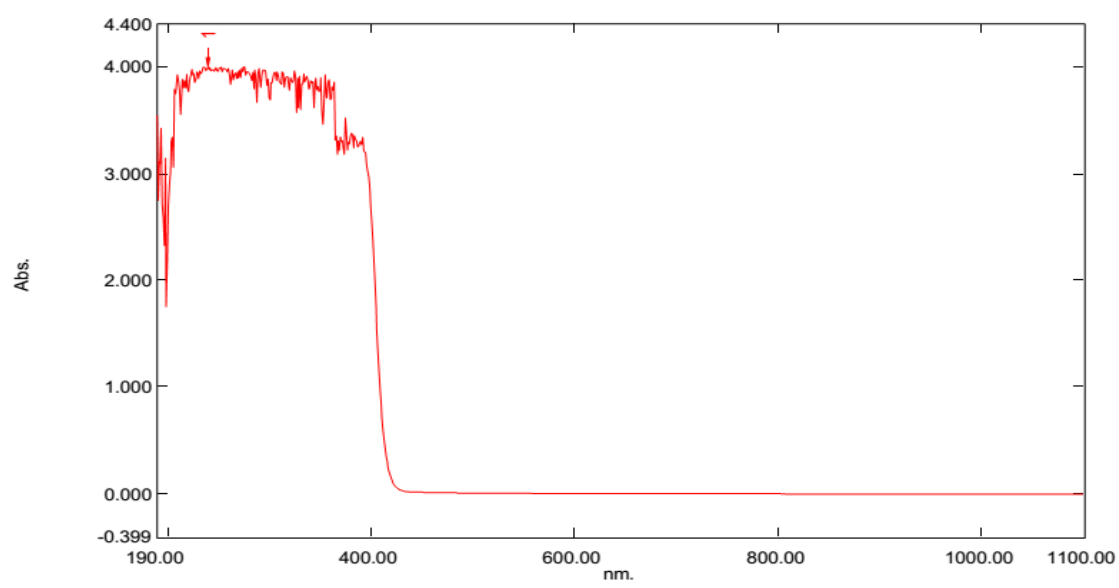

Fig. 1: UV spectra of atorvastatin calcium in 6.8 phosphate buffer

\section{FTIR studies $[22,23]$}

FT-IR spectra were recorded on a bruker spectrophotometer by using $\mathrm{KBr}$ discs in the range of $4000-450 \mathrm{~cm}^{-1}$. FT-IR analysis was performed using a sample of atorvastatin with various excipients at 1:1 mass/mass ratio. In the FTIR spectrum of sodium alginate powder, the various distinct peaks of alginate evident are those of the carbonyl at $1609 \mathrm{~cm}^{-1}$, hydroxyl group at $3429 \mathrm{~cm}^{-1}$, and carboxyl and carboxylate groups between 1000 and $1400 \mathrm{~cm}^{-1}$. The absorption band around 2880, 1656, 1421 and $1080 \mathrm{~cm}^{-1}$ corresponds to the stretching of- $\mathrm{CH}, \mathrm{COO}-, \mathrm{C}-\mathrm{O}-\mathrm{C},-\mathrm{CH}$ and- $\mathrm{CH}$, respectively.

FTIR spectra of atorvastatin showed presence of their characteristics band at $3362 \mathrm{~cm}^{-1}$ for $(-\mathrm{OH}), 3236 \mathrm{~cm}^{-1}$ for $(-\mathrm{NH})$, $2971 \mathrm{~cm}^{-1}$ for (-CH3), $2824 \mathrm{~cm}^{-1}$ for (-CH aromatic), $1649 \mathrm{~cm}^{-1}$ for $(\mathrm{C}=0), 1578 \mathrm{~cm}^{-1}$ for $(\mathrm{C}-\mathrm{N})$, and $1432 \mathrm{~cm}^{-1}$ for $(\mathrm{C}-\mathrm{C})$ functional groups. The cross-linking process with aluminium ion caused an obvious. The shift to higher wave number and a decrease in intensity of COO-stretching peaks, and a decrease in intensity of $1031 \mathrm{~cm}^{-1}$ peak of alginate. The results clearly revealed the compatibility of the drug with the excipients used in the formulation.

\section{Effect of concentration of sodium alginate}

Alginate derivatives are having mucoadhesive properties. In this study sodium alginate used as a coating material and that will be used in combination of different hydrophilic polymers in little concentrations were used. From the observed data, it was observed that increase in the molecular weight of the mucoadhesive polymers increases the drug entrapment efficacy. This can be due to increase in the viscosity of the polymeric solution which, the greater availability of aluminium binding sites in the network of polymeric chains. As a result formation of the more intact, denser matrix network, entrapping a higher amount of drug.

Overall results show that combination of alginate with other hydrophilic polymers, the release becomes more sustained. The decrease in conc. of sodium alginate, it gives less compact beads and provides lesser no. of binding sites along alginate chains for $\mathrm{Ca}+2 / \mathrm{Al}_{+3}$ ions resulting in a compact gel with less viscosity, which in turn increases the influx of divalent ions leading to decrease in encapsulation efficiency.

The higher the amount of sodium alginate in the beads, the lower the swelling rate that more sustained release was observed with the combination. From the studies, it was confirmed that stable beads were formed in sodium alginate at $3 \% \mathrm{w} / \mathrm{v}$ only then $2 \% \mathrm{w} / \mathrm{v}$. The beads prepared with $2 \% \mathrm{w} / \mathrm{v}$ were not observed much stable after drying time and they become changes in their appearance. At $4 \%$ $\mathrm{w} / \mathrm{v}$. sodium alginate solution is making difficulty in passing through syringe needle grade no. 22 at the time of discharge into curing medium because of their higher viscosity. So it is confirmed that out of all concentrations best one found to be $3 \% \mathrm{w} / \mathrm{v}$. and same used in further studies.

$3 \%$ sodium alginate $>2 \%$ sodium alginate

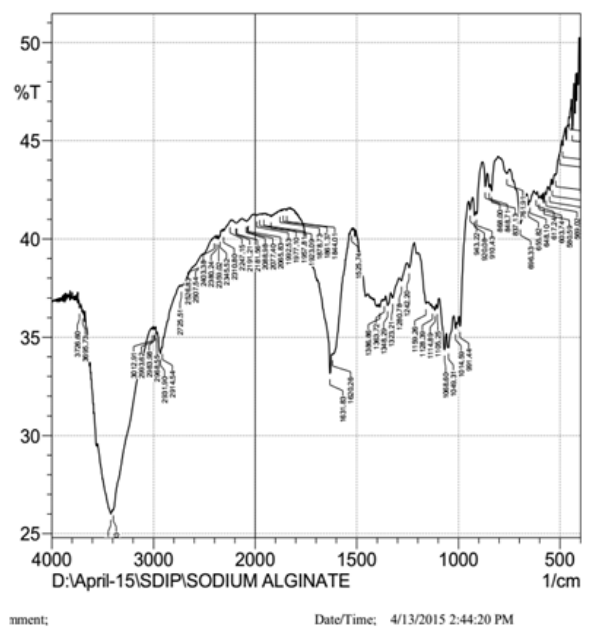

(a)

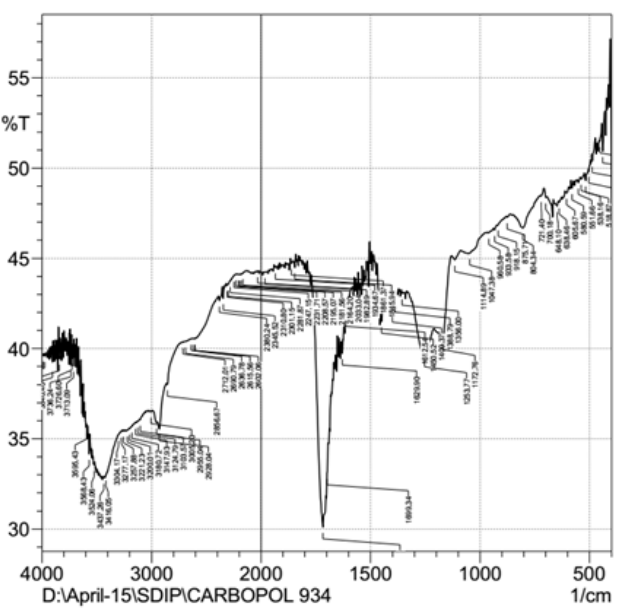

(b) 


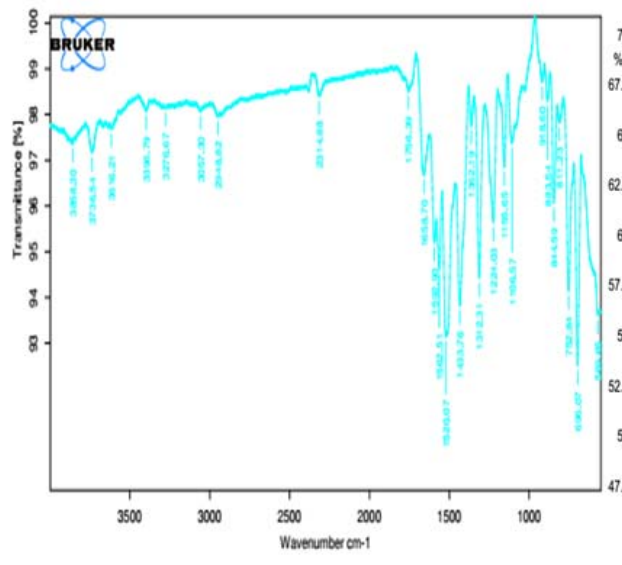

(c)

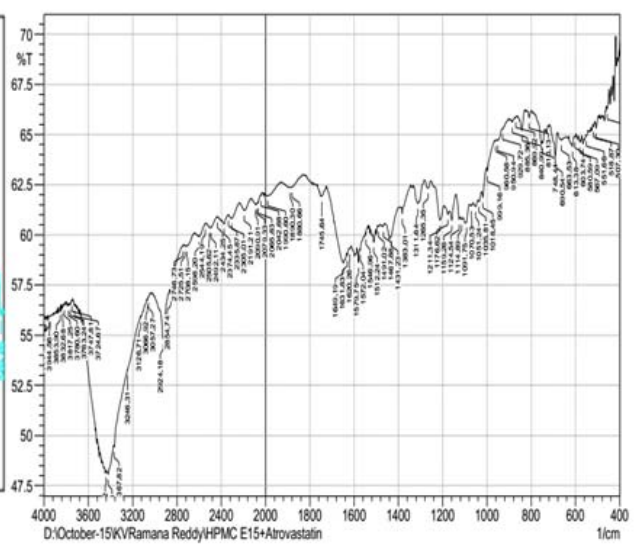

(d)

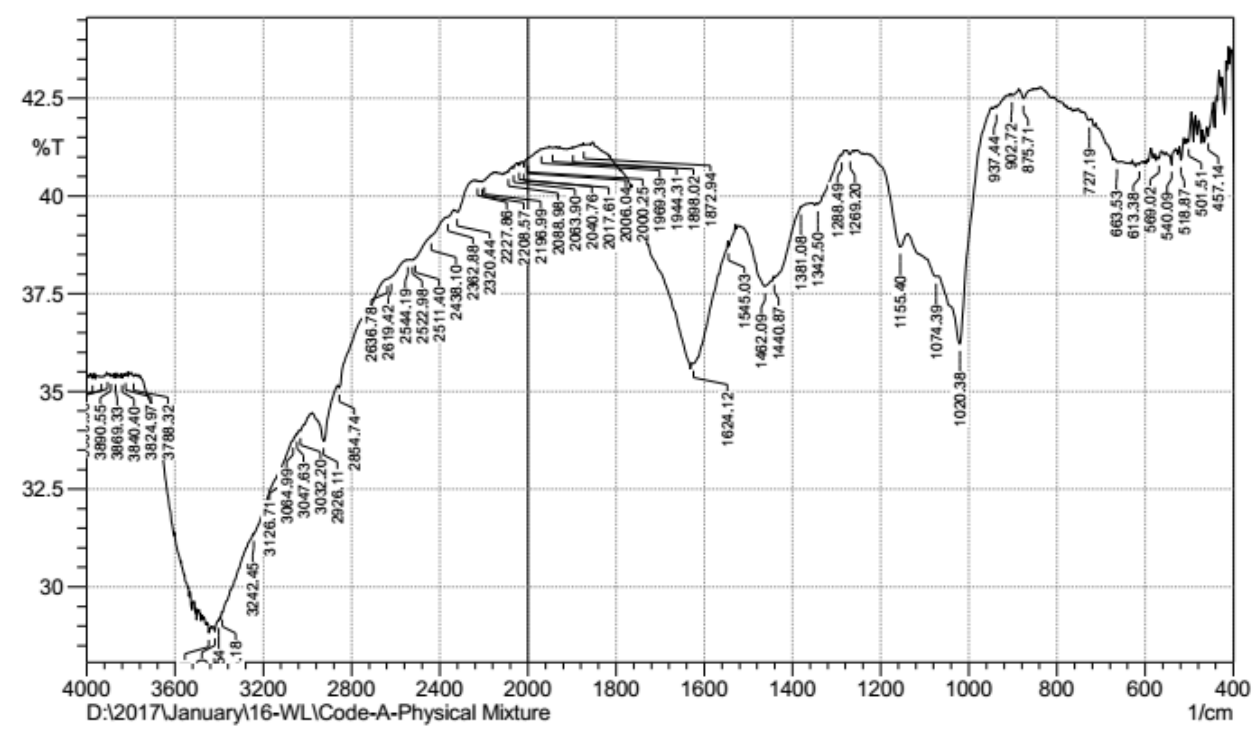

(e)

Fig. 2: FTIR spectras of a) pure sodium alginate, b) pure carbopol 934P, c) pure atorvastatin, d) mixture of HPMC $\mathrm{K} 15$ and atorvastatin and e) physical mixture

\section{Effect of stirring}

The rate of stirring has much influence in the formation of stable beads. After getting discharging of sodium alginate solutions into curing medium, beads were formed because of gelation reaction between alginate and curing agents. At slow rpm, the beads not developed properly in its strength and at higher rpm surface of beads were disrupted because of generation of high shear force. The stirring rate during crosslinking is believed to be a determining typical factor that affects the bead size and the yield. With very high stirring rate i.e. at $300 \mathrm{rpm}$ being responsible for the reduction in the yield Accordingly, the stirring rate was kept at $200 \mathrm{rpm}$ and was maintained with all formulation. This ensures that any variation in the bead size or morphology will be due to the variation in the composition.

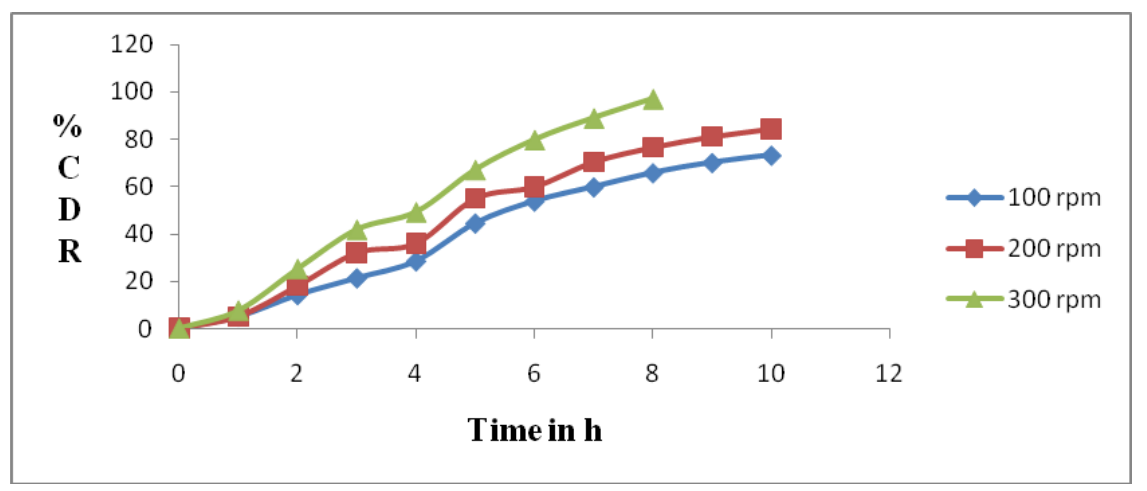

Fig. 3: Dissolution profile of optimized batch with different rpms. Results are given in mean of triplicate 


\section{Effect of curing time}

The curing time has a major role in developing rigid layer during gelation reaction. Upon extending curing beyond $30 \mathrm{~min}$ to $60 \mathrm{~min}$ beads becomes many compacts in comparison to $10 \mathrm{~min}$ and $20 \mathrm{~min}$. It was also confirmed that at $60 \mathrm{~min}$ the diffuses into curing medium and becomes less in drug encapsulating efficiency and makes delay in drug release. So curing time $1 \mathrm{~h}$ was selected for remaining studies.

The extent and rate of cross-linking depend on the valency of a cross-linking agent, molecular size of the drug and concentration of the agent as well as on the speed and curing time during processing. The water soluble and low molecular mass drugs have poor entrapment compared to insoluble and large molecular mass drugs.

The percentage entrapment efficiency decreased with an increase in the time of exposure to the cross linking agent may be due to the increased release of the drug from the matrix at the longer time of exposure. Since prolonged exposure in the curing medium caused greater loss of drug through cross-linked alginate microsphere. Accordingly, the cross linking time was kept constant $(1 \mathrm{~h})$ in all formulations.

\section{Effect of curing volume}

It was studied the effect of the volume of curing reagent on drug entrapment efficiency and drug release rate the microbeads were formulated by taking different volumes $(50,100$ and $150 \mathrm{ml})$ of the curing agent's solution. The entrapment efficiency was found to be increased with increase in the volume of curing agent up to $150 \mathrm{ml}$ and then entrapment efficiency has decreased the reason was contributed to chances of leaching of the drug in bulk volumes of the curing solution. The atorvastatin micro beads formulated by taking $100 \mathrm{ml}$ volume as curing reagent were showed good entrapment efficiency and desired drug release rate. Hence, $100 \mathrm{ml}$ of curing reagent was selected for further studies. Dissolution profiles of the optimised batch with different curing medium i.e. differ in volume were showed in fig. 4.
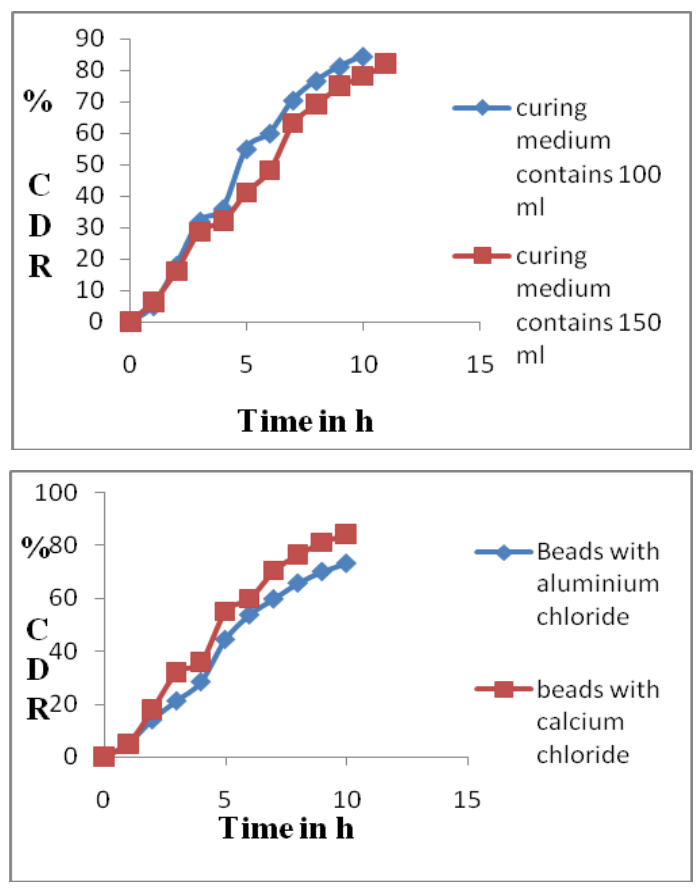

Fig. 4: Dissolution profiles of the optimized batch with different curing medium $100 \mathrm{ml}$ and $200 \mathrm{ml}$ (left side) and with different curing agents (right side). Results are given in mean of triplicate

\section{Effect of curing agent}

In present studies alginate beads prepared with different curing agents naming calcium chloride and aluminium chloride. The divalent compound $\mathrm{cacl}_{+2}$ form two-dimensional network when compared to aluminium chloride as it forms a three-dimensional network. Curing agent aluminium chloride has gained threedimensional networks in its orientation because of greater valence i.e. three in comparison to two of calc $_{2}$, and compact beads were formed with aluminium chloride at $5 \% \mathrm{w} / \mathrm{v}$ and make delay in drug release observed relatively. At lower concentrations of calcium chloride/aluminium chloride, the beads showed larger pores due to insufficient cross-linking which has resulting in lower drug entrapment, so for further studies was implemented in all formulations as it gives close compact network in the orientation of drug molecules in the polymer.

Although the aluminium has a small size as compared to calcium, the release of drug from the hydrogel beads cross-linked with aluminium chloride was found to be more sustained as compared to the beads crosslinked with calcium chloride. The reason is that aluminium carries an extra charge than calcium chloride. This threedimensional bonding results in extended cross-linking sites throughout whole beads. Hence, it releases the drug at a slow manner as compared to divalent compound calcium chloride. Dissolution profiles of the optimized batch with different curing agents were showed in fig. 4 .

\section{Role of needle and its position}

Information of stable spherical shape beads selection of needle size and its orientation plays a vital role. In the case of alginate which contains carbopol 934P [24] microspheres owing to its high viscosity in comparison to PVP and HPMC K15, the beads develops tail while in passing through the needle into the curing medium, so beads not forms spherical shape and gives an ovate/cylindrical shape like.

So to avoid abnormal shape of beads, the position of needle have to keep in divert position like, this modification has to make only in formulation contains sodium alginate in combination with carbopol 934P only. As the size of needle increases, the diameter of the needle decreases. The alginate beads prepared with different sizes of needles were observed.

\section{Morphology and size distribution}

Morphology of the various formulations of sodium alginate microspheres prepared was found to be in discrete and spherical appearance. The SEM photomicrographs of the dried alginate microspheres are shown in fig. 5. The surface of the alginate microspheres was rough due to a higher concentration of sodium alginate and uniformly dispersed of drug molecular level in the alginate matrices.

\section{Effect of sodium alginate on drug entrapment efficiency}

The higher viscosity of sodium alginate with different hydrophilic polymers at selected concentration will leads to decrease the rate of diffusion of drug into curing medium which would result in higher drug entrapment efficiency, this may be reason to greater availability of no. of active binding sites along polymeric chains and ultimately the degree of cross linking sites as the amount of alginate increased.

\section{Incorporation efficiency of microspheres}

The incorporation efficiency increased progressively with increasing sodium alginate concentration. An increase in the alginate concentration resulted in the formation of larger microspheres entrapping greater amounts of the drug. This may be attributed to the greater availability of active calcium-binding sites in the polymeric chains and, consequently, the greater degree of crosslinking as the quantity of sodium alginate increased.

The incorporation efficiencies were generally higher for the beads cross-linked with $\mathrm{Al}_{+3}$ as compared to the beads crosslinked with $\mathrm{Ca}+2$. This may be attributed to the formation of nonporous alginate beads due to an increase in the apparent cross-linking density in presence of cations i.e. $\mathrm{Al}_{+3}$ which prevent the diffusion of the drug out of the beads at the time of curing. 

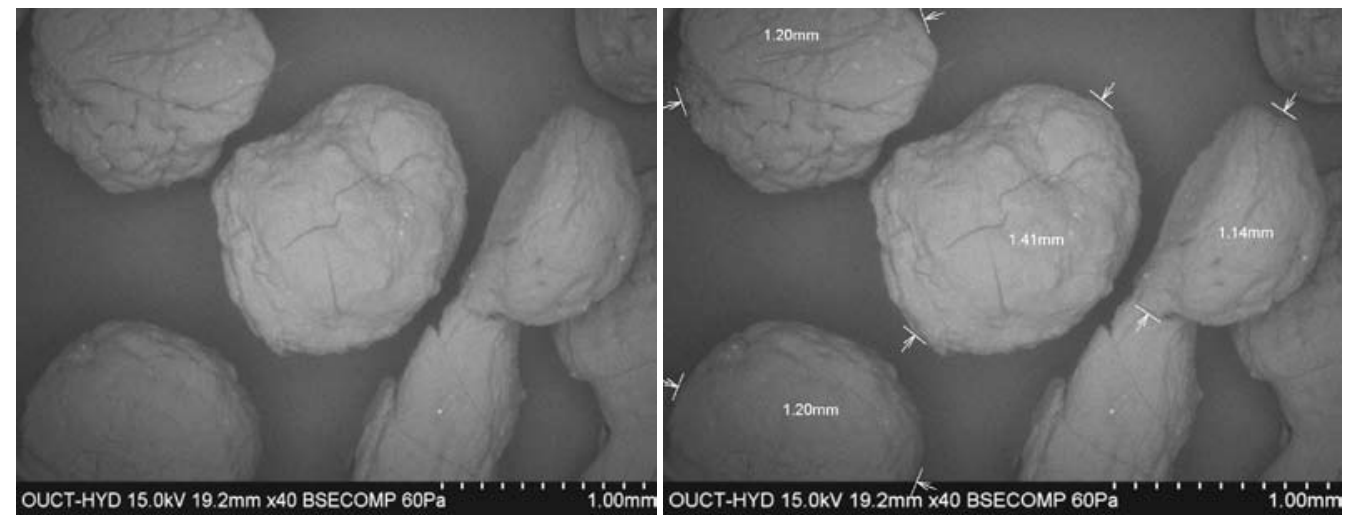

Fig. 5: SEM picture of mucoadhesive microbeads

Table 5: Entrapment efficiency, percentage yield observed from the atorvastatin mucoadhesive microbeads formulated by employing various formulations

\begin{tabular}{lllll}
\hline Formulation & $\begin{array}{l}\text { Theoretical } \\
\text { drug content(mg) }\end{array}$ & $\begin{array}{l}\text { Practical } \\
\text { drug content(mg) }\end{array}$ & $\begin{array}{l}\text { Encapsulation } \\
\text { efficiency* }\end{array}$ & $\begin{array}{l}\text { Yield } \pm \text { SD) } \\
\text { (\% } \pm \text { SD) }\end{array}$ \\
\hline A1 & 20 & 11.78 & $58.90 \pm 0.53$ & $47.67 \pm 1.78$ \\
B1 & 12.20 & $61.21 \pm 1.34$ & 1095 \\
C1 & 20 & 11.01 & $55.05 \pm 0.41$ & $48.34 \pm 2.23$ \\
D1 & 20 & 10.78 & $53.90 \pm 0.32$ & $48.79 \pm 0.59$ \\
E1 & 20 & 11.56 & $57.80 \pm 2.12$ & 1074 \\
\hline
\end{tabular}

${ }^{*} n=3$ (average \pm SD).

The low incorporation efficiency of alginate beads cross-linked with $\mathrm{Cacl}_{+2}$ could be attributed to the formation of porous beads ensuring the diffusion of the drug out of the beads at the time of curing.

\section{Swelling index}

Polymer swelling and cross-linking are intimately connected to the release kinetics of the drugs from the swollen matrix. In order to investigate this effect, swelling results were obtained. Swelling of the beads was measured in terms of their percentage of water uptake at a selected time intervals. Swelling of cross linking alginate beads was observed little in acidic medium, In contrast to this, the rate of swelling will be more than triple times in presence of alkaline medium as it undergoes relaxation of the polymer.

Table 6: Percentage of swelling index with $3 \% \mathrm{w} / \mathrm{v}$ sodium alginate with different hydrophilic polymers $(0.3 \% \mathrm{w} / \mathrm{v})$, Each reading taken in triplicate

\begin{tabular}{llll}
\hline Time (h) & Alg-carbopol 934p & Alg-HPMC K15 & Alg-PVP* \\
\hline 2 (Acidic medium) & $0.75 \pm 0.23$ & $1.5 \pm 0.12$ & $3.375 \pm 0.23$ \\
2 (Alkaline medium) & $1.125 \pm 0.34$ & $4.5 \pm 0.09$ & $8.87 \pm 0.69$ \\
\hline
\end{tabular}

$n=3$ (average \pm SD)

Erosion test

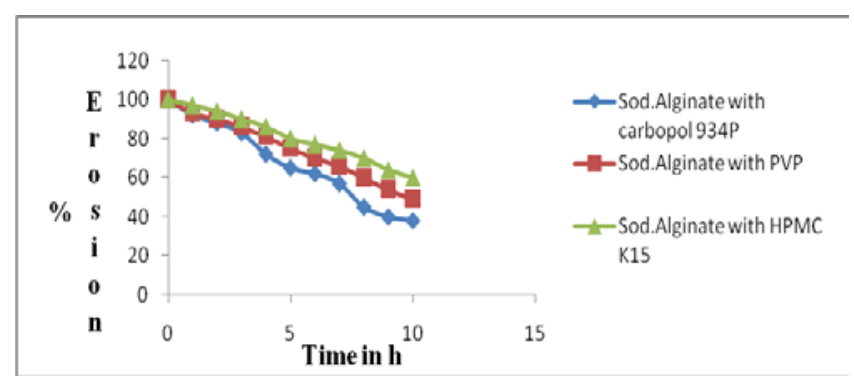

Fig. 6: Erosion studies of different formulations, * Results are given in mean of triplicate

\section{Wash off test}

It gives knowledge regarding the ability of the polymer to adhere to the GI tract mucosa when it is thoroughly and continuously washed by 6.8 phosphate buffer/GI fluid. Microspheres with a coat consisting of sodium alginate and a mucoadhesive polymer exhibited good mucoadhesive properties as indicated by the in vitro wash-off test. Higher the adhesion to mucosa as well as greater 
localisation of beads forms at the site of absorption if beads have a higher value of mucoadhesion rate.

Beads prepared with carbopol 934P has higher mucoadhesion value, the reason due to the free carboxyl group which has high ability to form Covalent bonding with the mucin sites which present in mucous membrane whereas HPMC K15 polymer contains hydroxyl $(-\mathrm{OH})$ groups. A hydroxy group present in HPMC $\mathrm{K} 15$ is less polar in comparison to the free carboxyl group of carbopol 934P. Hence a carbopol bead shows higher mucoadhesion as compared to HPMC.

The study details reveals in vitro wash off was faster at simulated intestinal fluid ( $\mathrm{pH}$ 6.8) than that simulated GI fluid ( $\mathrm{pH}$ 1.2). $\mathrm{pH}$ of in vitro wash off medium has pronounced effect on solubility, hydration and mucoadhesivenss of the polymer. The polymers exhibiting relaxation property depends upon $\mathrm{pH}$.

The solubility of beads was faster at 6.8 buffer medium may be due to ionization of carboxy acid group i.e. sod. Alginate and other polymers. The decreased mucoadhesion of beads in phosphate buffer may result from erosion of aluminium ions which form a cross-linked structure.

At higher solubility beads shows less mucoadhesive strength. The results of in vitro wash off test indicated that atorvastatin beads had fairly good mucoadhesive properties. The prepared beads would adhere to walls of mucus, thus restricting gastric emptying and prolong the residence tome of atorvastatin beads at absorption site, thereby it is possible to improve and increase the rate of bioavailability.

Table 7: Result of in vitro wash-off test of micro beads in $0.1 \mathrm{~N}$ Hcl

\begin{tabular}{llll}
\hline Time (h) & Alg. with carbopol 934P & Alg with HPMC & Alg with PVP* \\
\hline 1 & $88.67+1.32$ & $75.76 \pm 5.67$ & $79.78 \pm 4.12$ \\
2 & $80.45 \pm 3.45$ & $69.89 \pm 3.56$ & $70.13 \pm 0.12$ \\
4 & $60.78 \pm 3.67$ & $50.45 \pm 5.98$ & $51.21 \pm 8.34$ \\
6 & $42.32 \pm 4.23$ & $39.21 \pm 3.32$ & $40.12 \pm 4.83$ \\
8 & $34.78 \pm 8.65$ & $23.32 \pm 4.43$ & $30.23 \pm 2.78$ \\
\hline
\end{tabular}

$* n=3$ (average $\pm \mathrm{SD}$ )

Table 8: Result of in vitro wash-off test of microcapsules in 6.8 phosphate buffer

\begin{tabular}{llll}
\hline Time (h) & Alg. with carbopol 934P & Alg with HPMC & Alg with PVP \\
\hline 1 & $75.12 \pm 1.23$ & $60.34 \pm 1.56$ & $70.23 \pm 5.45$ \\
2 & $50.23 \pm 2.45$ & $41.23 \pm 3.45$ & $47.56 \pm 2.45$ \\
4 & $29.56 \pm 0.23$ & $20.12 \pm 4.56$ & $25.67 \pm 6.03$ \\
6 & $15.23 \pm 8.95$ & $9.456 \pm 9.43$ & $12.56 \pm 4.12$ \\
8 & $5.78 \pm 3.76$ & 0 & $3.45 \pm 3.32$ \\
\hline
\end{tabular}

Every reading taking in triplicate i.e. $n=3$ (average \pm SD)

\section{X-ray diffraction studies}

The diffraction pattern of the pure drug showed characteristic highintensity diffraction peaks at $8.94,9.34,10.01,10.38,11.65,12.20$, $16.84,19.26,21.36,22.50,23.11$, and 23.51, which indicates that the drug is dispersed in the crystalline form that is also confirmed by DSC results. It is confirmed that the reflections of the pure drug match satisfactorily with the reflections of the drug in the microbeads formulation. Thus, it can be concluded that the polymorph of the pure drug was the same as that of atorvastatin polymorph incorporated in microbeads, and there are no transformation took place during the manufacturing process and storage.

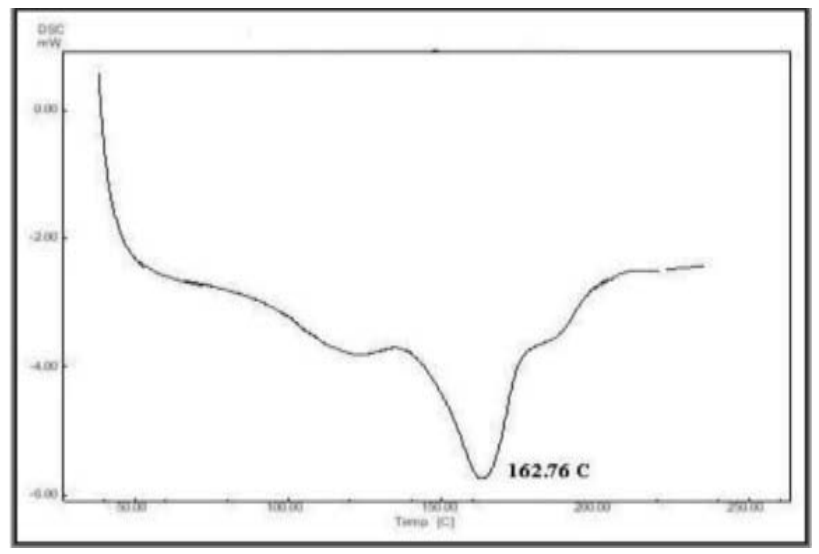

(a)

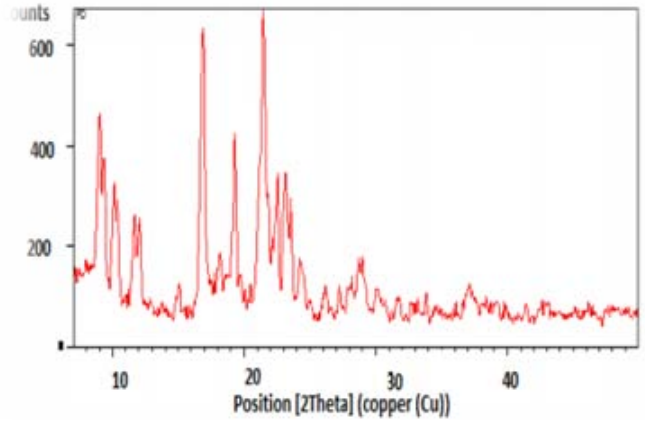

(b)

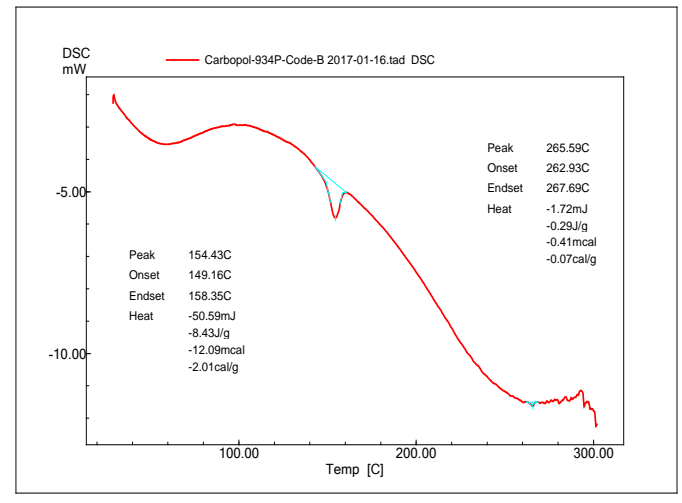

(c) 


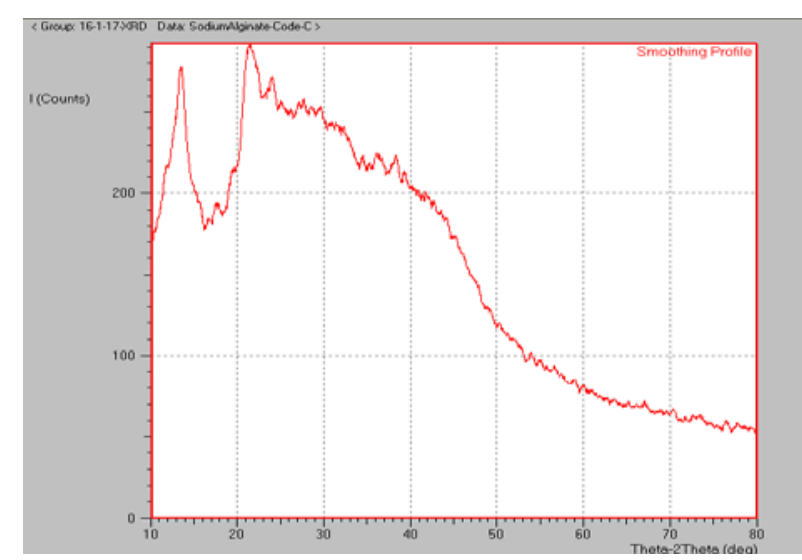

(d)

\section{In vitro dissolution}

Alginate is insoluble in acidic $\mathrm{pH}$ i.e. $0.1 \mathrm{~N} \mathrm{Hcl}$, and at low $\mathrm{pH}$, the number of positively charged ions is high, and they minimise the electrical repulsion between the negatively charged alginate molecules. Alginate is protonated into the insoluble form of alginic acid molecules. Thus, penetration of dissolution fluid through the polymer matrix is hindered, and the percentage of drug released due to diffusion through the polymer network was minimal at $\mathrm{pH} 1.2$ for all prepared beads.

The rate of drug release from alginate-hydrophilic polymers i.e. carbopol 934P, HPMC K15 M and PVP. Beads formulated with a higher degree of cross-linking was more sustained than the beads formulated with a lower degree of cross-linking. Again, the release rate of atorvastatin in acid was found to be slower and more sustained. This may be due to the stability of alginate at acidic $\mathrm{pH}$

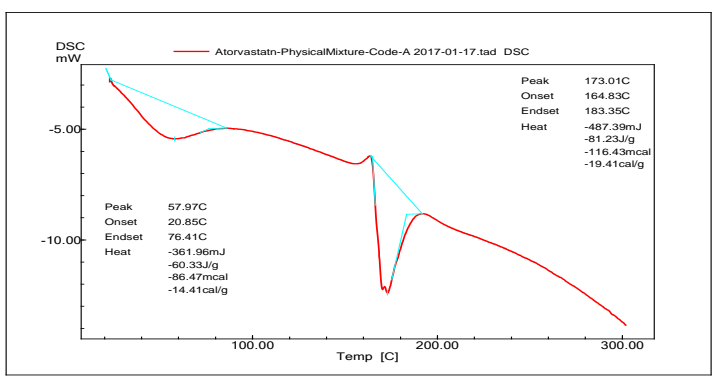

(e)

Fig. 7: a) X-ray diffraction of pure atorvastatin and b) DSC spectra of pure atorvastatin calcium, c) DSC of pure carbopol 934P d) X-ray diffraction of pure sodium alginate and (e) DSC spectra of physical mixture

and the conversion of calcium/aluminium alginate to the insoluble but swelling alginic acid.

The higher amount of drug release in 6.8 phosphate buffer than acidic buffer may be due to the higher swelling rate of the alginates in phosphate buffer medium. The presence of carbopol 934P and HPMC in the beads added to the network structure of the beads and in forced the degree of crosslinking due to its interaction with aluminium ions. This produces tight packing which disintegrates and dissociates slowly with subsequent slow release even in the intestinal phase.

When $\mathrm{pH}$ is increased i.e. at $6.8 \mathrm{pH}$ phosphate buffer, drug release is increased up to the maximum level. Deprotonation of alginic acid occurs at higher $\mathrm{pH}$ values. It will draw dissolutiflaid into the beads, which causes swelling of beads and burst apart of the drug.

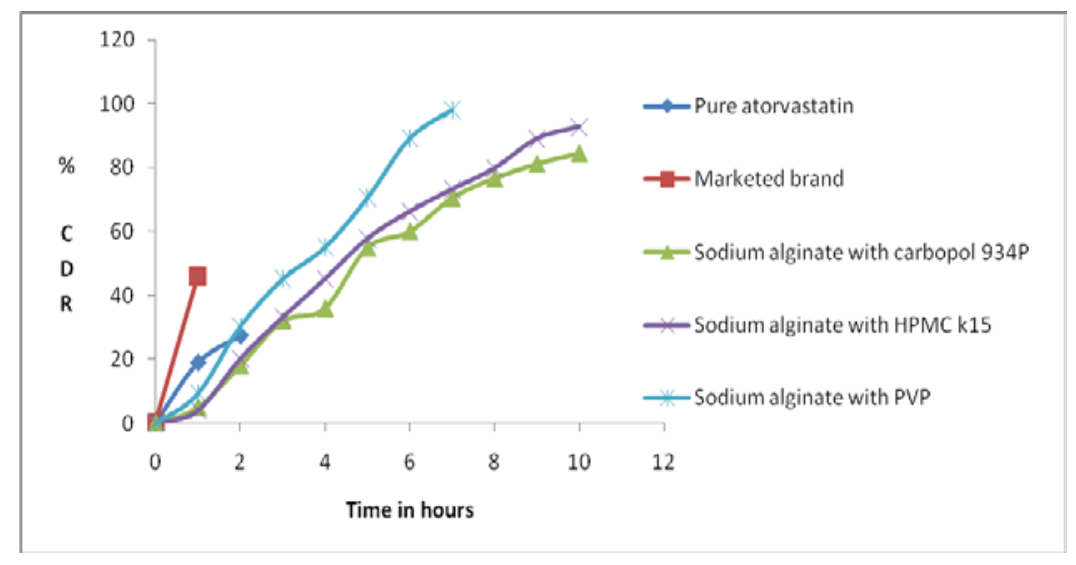

Fig. 8: Dissolution profiles of pure atorvastatin, marketed brand and other formulations, *Results are given in mean of triplicate

As the polymer concentration increased, diffusion resistance to drug release also increased, which, in turn, decreased in drug release [24-26].

Positively charged groups of HPMC K15 strongly interact with alginate and atorvastatin ions, thus reducing both swelling and release probably due to protonation of carboxylated functional groups from Na-alginate molecules, and based on ficks law of diffusion, it may be inferred that as the viscosity of the formulation increases, molecular diffusivity (diffusion coefficient) and percentage release of drug also decreases

The results indicated the more sustained effect with an increase in the viscosity of sodium alginate with different hydrophilic polymers. The first phase might be for the negligible dissociation of alginate beads in the acidic buffer and the drug release mainly based on drug diffusion through the formation of small pores and cracks upon swelling process. The second phase compared to initial phase exhibited a sustained release pattern, which was accompanied by rapid alginate disintegration of alginate in phosphate buffer than acidic medium. The sodium alginate combination with other hydrophilic polymers in the formulation greatly influenced the steady state release of atorvastatin from the alginate beads.

Swelling of the polymer also leads to the formation of the matrix, thereby retarding the release of drug from the formulation $[27,28]$. The higher mucoadhesion of carbopol 934P microspheres may also be attributed to the higher molecular weight of carbopol than HPMC [29]. These polymers are often used as a rate-controlling membrane to modulate the drug release from dosage forms with organic or aqueous coating techniques [30-33]. The principle of gelation or crosslinking of sodium alginate with aluminium chloride is based on the formation of a tight junction between the residues of guluronic acid. The number of the apparent cross-linking points within the formed aluminium alginate gel beads increased with increasing sod. 
alginate concentration in the formulation. This increase in the intensity of crosslinking density delayed the alginate gel disintegration in $6.8 \mathrm{pH}$ phosphate buffer due to the retardation of aluminium $_{3}+$ exchange with $\mathrm{Na}+$. Increased alginate gel density per unit volume also affected the decreased pore size within the gels, and thus atorvastatin release becomes slow.

The release behaviour of alginate microspheres, produced by ionotropic external gelation causes precipitation with different gelling agent's ex. $\mathrm{Cacl}_{+2}$ and $\mathrm{Alcl}_{+3}$ depend upon the valency of ions and size of the cations of the respective cross-linking agent. To investigate this aspect, the sodium alginate $(3.0 \% \mathrm{w} / \mathrm{v})$ beads were prepared via cross linking in $5 \% \mathrm{w} / \mathrm{v}$ solution of $\mathrm{cacl}_{+2}$ and $\mathrm{alcl}_{+3}$ respectively.

Drug release from the microspheres depends on the viscosities of the various polymers. Their release profile in 6.8 phosphate buffer was depicted in fig. 10. The sustained release pattern was observed in all formulations. The results obtained can be explained on the basis of the extent of cross-linking in the microspheres. Calcium chloride being a divalent forms two-dimensional network structure with sodium alginate inside the alginate matrices. In the case of $\mathrm{Al}_{+3}$ alginate microspheres, the delay was due to the ability of $\mathrm{Al}_{+3}$ to form three-dimensional network structure with the sodium alginate inside the lattice of microspheres. This three-dimensional bonding results in an extended crosslinking through the whole microsphere, producing hard and compact alginate microspheres with less water uptake and thus leads to slow removal of $\mathrm{Al}_{+3}$ due to the exchange of ions with $\mathrm{Na}_{+}$in the 6.8 phosphate buffer. As a result, the swelling of the beads are delayed leading to slow disintegration/ rupture of bead surface.

Kinetic modelling in vitro dissolution data was analyzed by different kinetic models in order to find out the $\mathrm{n}$ value, which describes the drug release mechanism. The values of coefficient of correlation $\left(\mathrm{R}^{2}\right)$ obtained for the respective model are listed in following table 9. Models with the highest correlation coefficient (R2) were judged to be the most appropriate model for the in vitro release study.

The values of $\mathrm{n}$ for the release of atorvastatin from the alginate microspheres range between 1.376 and 2.927 , indicating that the drug release from the microspheres followed the anomalous transport and super case-II transport mechanism controlled by swelling and relaxation of the polymer chains. Prepared micro beads were best fitted Higuchi model which indicated the drug release by diffusion in the slow and sustained way.

Table 9: Release kinetics data of all formulations

\begin{tabular}{|c|c|c|c|c|c|c|}
\hline Batch code & Zero order & First order & Higuchi matrix* & Korsmeyers Peppas* & Hixon crowell equation* & n value \\
\hline $\mathrm{A} 1$ & $\mathrm{R}^{2}=0.975$ & $\mathrm{R}^{2}=0.734$ & $\mathrm{R}^{2}=0.930$ & $\begin{array}{l}\mathrm{R}^{2}=0.866 \\
\text { slope }=1.567 \mathrm{x}+0.529\end{array}$ & $\begin{array}{l}\mathrm{R}^{2}=0.885 \\
\text { slope }=0.853 \mathrm{x}+4.976\end{array}$ & 0.853 \\
\hline B1 & $\mathrm{R}^{2}=1$ & $\mathrm{R}^{2}=1$ & $\mathrm{R}^{2}=0.725$ & $\begin{array}{l}\mathrm{R}^{2}=0.855 \\
\text { slope }=1.476 \mathrm{x}+0.544\end{array}$ & $\begin{array}{l}\mathrm{R}^{2}=0.896 \\
\text { slope }=0.740 \mathrm{x}+5.075\end{array}$ & 1.476 \\
\hline $\mathrm{C} 1$ & $\mathrm{R}^{2}=1$ & $\mathrm{R}^{2}=0.986$ & $\mathrm{R}^{2}=0.765$ & $\begin{array}{l}\mathrm{R}^{2}=0.859 \\
\text { slope }=1.376 \mathrm{x}+0.544\end{array}$ & $\begin{array}{l}\mathrm{R}^{2}=0.996 \\
\text { slope }=0.780 x+5.075\end{array}$ & 1.376 \\
\hline D1 & $\mathrm{R}^{2}=0.979$ & $\mathrm{R}^{2}=0.725$ & $\mathrm{R}^{2}=0.930$ & $\begin{array}{l}\mathrm{R}^{2}=0.866 \\
\text { slope }=1.637 \mathrm{x}+0.509\end{array}$ & $\begin{array}{l}\mathrm{R}^{2}=0.881 \\
\text { slope }=0.893 x+5.012\end{array}$ & 1.637 \\
\hline E1 & $\mathrm{R}^{2}=0.994$ & $\mathrm{R}^{2}=0.756$ & $\mathrm{R}^{2}=0.906$ & $\begin{array}{l}\mathrm{R}^{2}=0.791 \\
\text { slope }=1.796 \mathrm{x}+0.622\end{array}$ & $\begin{array}{l}\mathrm{R}^{2}=0.870 \\
\text { slope }=0.854 \mathrm{x}+5.173\end{array}$ & 1.796 \\
\hline Marketed brand & $\mathrm{R}^{2}=1$ & $\mathrm{R}^{2}=1$ & $\mathrm{R}^{2}=1$ & $\begin{array}{l}\mathrm{R}^{2}=0.825 \\
\text { slope }=1.503 \mathrm{x}+0.609\end{array}$ & $\begin{array}{l}\mathrm{R}^{2}=1 \\
\text { slope }=2.927 \mathrm{x}+1\end{array}$ & 1.503 \\
\hline Pure drug & $\mathrm{R}^{2}=0.952$ & $\mathrm{R}^{2}=0.831$ & $\mathrm{R}^{2}=0.999$ & $\begin{array}{l}\mathrm{R}^{2}=1 \\
\text { slope }=2.927 \mathrm{x}+0.999\end{array}$ & $\begin{array}{l}\mathrm{R}^{2}=0.871 \\
\text { slope }=2.619 \mathrm{x}+1\end{array}$ & 2.927 \\
\hline
\end{tabular}

${ }^{*} n=3$ (average $\pm \mathrm{SD}$ )

\section{CONCLUSION}

This study reveals that the sustained release of atorvastatin microbeads can be successfully achieved by ionotropic gelation technique using sodium alginate as a coating polymer and different hydrophilic polymers as release rate modifiers. To meet this objective, the microbeads were formulated by varying the processing conditions. The in vitro studies demonstrated that the microbeads formulated with $3 \% \mathrm{w} / \mathrm{v}$ sodium alginate as coating polymer with $0.3 \% \mathrm{w} / \mathrm{v}$ of carbopol $934 \mathrm{P}$ under the presence of 100 $\mathrm{ml}$ at $5 \% \mathrm{w} / \mathrm{v}$ aqueous aluminium chloride solution as curing reagent with $200 \mathrm{rpm}$ offered sustained release rates for $10 \mathrm{~h}$. The specifications of alginate beads depend on the composition of the beads. The addition of sodium alginate to viscosity modifiers i.e. as in form of carbopol 934P, pvp and hpmc k15 increases the drug entrapment efficiency and swelling property into these beads than alginate alone. As this method developed is highly simple, fast and reproducible. A delay in the release of atorvastatin was observed for the combination of sod. alginate and carbopol 934P beads.

The value of $\mathrm{n}$ is 1.567 for the formulation which contains a combination of sodium alginate with carbopol 934P. The $n$ value confirms that drug release from beads was followed super case-II transport mechanism indicates that drug control by swelling and relaxation of polymer chains. The optimized mucoadhesive microcapsules exhibited good flow properties, mucoadhesive potential, better drug entrapment efficiency, and the desired release characteristics. Matrix swelling induced by 6.8 phosphate buffer and drug release is proved to be a function of $\mathrm{pH}$ based. Thus, this study concludes that the performance of the microbeads can be altered by changing the processing variables involved in the production of stabled cross-linked atorvastatin microbeads.

\section{ACKNOWLEDGEMENT}

The authors are grateful to Aizant labs, Hyderabad for providing gift sample of atorvastatin and Osmania University, Hyderabad, India for completion of compatibility studies, DSC and X-ray diffraction studies for the samples.

\section{CONFLICTS OF INTERESTS}

Declare none

\section{REFERENCES}

1. Tekade BW, Jadhao UT, Kale VS, Thakare VM, Chaudhari KP, Patil VR. Formulation development and evaluation of mucoadhesive tablet containing cetirizine dihydrochloride by using different mucoadhesive polymers. Indo Am J Pharm Res 2013;3:6009-19.

2. Shivendra Agarwal, Faraz Zamil, Lokendra Singh, Amit Saxena. Formulation and evaluation of floating beads of diltiazem HCL. Int J Curr Pharm Res 2016;4:38-42.

3. Sriamornsak $P$, Nunthanid J, Luangtana-anan $M$, Puttipipatkhachorn S. Alginate-based pellets prepared by extrusion/spheronization: A preliminary study on the effect of additive in granulating liquid. Eur J Pharm Biopharm 2007;67:227-35.

4. Nethaji R, Shareef S, Palanivelu M, Surendiran SN, Ganesan B. Formulation and evaluation of propranolol hydrochloride 
microspheres by ionic gelation technique. Int J Pharm Chem Biol Sci 2015;5:407-16.

5. Radonjic M, Wielinga P, Verschuren L, Kelder T, Kooistra T. Systems biology analysis unravels the complementary action of combined rosuvastatin and atorvastatin therapy. Pharmacogenet Genomics 2012;22:837-46.

6. Taha EL, Al Saidan S, Samy AM, Khan MA. Preparation and in vitro characterization of self nanoemulsified drug delivery system of all trans retinol acetate. Int J Pharm 2004;28:109-19.

7. Chowdary DPR, Srinivas L. Mucoadhesive drug delivery system: a review of current status. Indian Drugs 2000;37:400-6.

8. Sasre T, Venkitachalam P. Buccoadhesive tablets of nefidipine: standardization of a novel buccoadhesive erodible carrier. Drug Dev Ind Pharm 1994;20:3005-14.

9. Kalambe RN, Baviskar DT, Thakare VM, Jadhav SD, Jadhav CM, Tekade BW, et al. Formulation and evaluation of fast dissolving oral film of levocetirizine dihydrochloride. Int J Pharm Sci 2013;5:337-41.

10. Corsini A, Bellosta S, Baetta R, Fumagalli R, Paoletti R, Bernini F. New insights into the pharmacodynamic and pharmacokinetic properties of statins. Pharmacol Ther 1999;84:413-28.

11. Raimar L, Jae Seung K, Gordon LA. Pharmacokinetics of an immediate release, a controlled release and a two pulse dosage form in dogs. Eur J Pharm Biopharm 2000;60:17-23.

12. Das MK, Senapati PC. Evaluation of furosemide-loaded alginate microspheres prepared by ionotropic external gelation technique. Acta Pol Pharm 2007;64:253-62.

13. Yaddalapudi S, Palla J. Formulation, and evaluation of metformin hydrochloride sustained released microspheres. J Comprehensive Pharm 2014;1:136-41.

14. Chang X, Weng T, Zhao X, Chen H, Gao Z, Yang Y, et al. A study of microemulsion systems for transdermal delivery of triptolide. J Controlled Release 2004;98:427-36.

15. Yadav A, Jain DK. Formulation and evaluation of mucoadhesive microspheres of propranolol hydrochloride for sustained drug delivery. Asian J Pharm Med Sci 2011;1:1-8.

16. Du Pasquier A, Disma F, Bowmer T, Gozdz AS, Amatucci G, Tarascon JM. Differential scanning calorimetry studies of lithium ion and the reactivity of carbon anodes in plastic lithium ion batteries. J Electrochem Soc 1998;145:472-7.

17. Deshpande RD, Gowda DV, Mahammed N. Design of Pistacia lentiscus (mastic gum) controlled release spheroids and investigating the influence of roll compaction. Industrial Crops Products 2013;44:603-10.

18. Cosijins A, Nizet D, Nikolokakis I. Porous pellets as drug delivery system. Drug Dev Ind Pharm 2009;35:655-62.

19. Swamy NG, Rupa V, Abbas Z, Dasankoppa FS. Formulation and evaluation of nanosuspensions for enhancing the dissolution of poorly soluble mebendazole. Indian Drugs 2010;47:47-54.

20. Wei H, Qing D, De-Ying C, Bai X, Li-Fang F. In vitro and in vivo studies of pectin/ethylcellulose film-coated pellets of 5fluorouracil for colonic targeting. J Pharm Pharmacol 2008;60:35-44

21. Surjyanarayan M, Hemangini R, Bhavdip J, Mikesh P, Rajesh KS. Release kinetic modeling of atorvastatin calcium loaded self microemulsifying drug delivery system. Elixir Pharm 2012;53:11725-9.

22. Marzouk AM, Kassem AA, Samy AM, Amer RI. Comparative evaluation of ketoconazole- $\beta$-cyclodextrin systems prepared by coprecipitation and kneading. Drug Discovery Therapy 2010;4:380-7.

23. Stuart B. Infrared spectroscopy-Fundamental and application, John Wiley and Sons; 2004. p. 46-63.

24. Sathali AAH, Varun J. Formulation, development and in vitro evaluation of candesartan cilexetil mucoadhesive microbeads. Int J Curr Pharm Res 2012;4:109-18.

25. Shahira F, El-Menshawe, Rasha M Kharshoum, Doa S Hamad, Abdelkhalek Halawa. Effect of biodegradable co-polymers and divalent cations on the sustained release ability of propranolol hydrochloride loaded biomaterial. Int J Pharm Pharm Sci 2011;8:311-7.

26. Abou el Ela AF, Hassan MA, E Maraghy DA. Ketorolac tromethamine floating beads for oral application: characterization and in vitro/in vivo evaluation. Saudi Pharm J 2014;22:349-59.

27. Gurpreet Arora, Karan Malik, Inderbir Singh, Sandeep Arora, Vikas Rana. Formulation and evaluation of controlled release matrix mucoadhesive tablets of domperidone using Salvia plebeian gum. J Adv Pharm Technol Res 2011;2:163-9.

28. Mitra Jelvehgari, Parvin Zakeri-Milani, Fatemeh Khonsari. Comparative study of in vitro release and mucoadhesivity of gastric compacts composed of multiple unit system/bilayered discs using direct compression of metformin hydrochloride. Bioimpacts 2014;4:29-38.

29. Nanjwade BK, Parikh KA, Deshmukh RV, Nanjwade VK, Gaikwad KR. Development and evaluation of Intranasal mucoadhesive microspheres of neostigmine bromide. Pharm Anal Acta 2011;2:118.

30. Lin SY, Lin KH, Li MJ. Formulation design of double-layer in the outer shell of the dry-coated tablet to modulate lag time and time-controlled dissolution function: studies on micronized ethylcellulose for dosage form design. AAPS Journal 2004;6:1-6.

31. Neau SH, Howard MA, Claudius JS, Howard DR. The effect of the aqueous solubility of xanthine derivatives on the release mechanism from ethylcellulose matrix tablets. Int J Pharm 1999;179:97-105.

32. Siepmann F, Hoffmann A, Leclercq B, Carlin B, Siepmann J. How to adjust desired drug release patterns from ethylcellulose-coated dosage forms. J Controlled Release 2007;119:182-9.

33. Mortazavi SA, Moghimi HR. Effect of surfactant type and concentration on the duration of mucoadhesion of carbopol 934 and HPMC solid compacts. Iran J Pharm Res 2010;2:191-9.

\section{How to cite this article}

- Kandi Venkata Ramana Reddy. The role of the needle in the formulation of $\mathrm{pH}$ sensitive swellable microbeads prepared with hydrophilic polymers for atorvastatin and their characterization studies. Int J Appl Pharm 2017;9(3):20-30. 